九州大学学術情報リポジトリ

Kyushu University Institutional Repository

Development of an Intelligent Robot for an Agricultural Production Ecosystem (VIII) : Improvement of Predator-Prey Model and Analysis of the Activity of Snail in Paddy by Image Processing-

Yamaguchi, Yusuke

Laboratory of Agricultural Ecology, Division of Agricultural Ecology, Department of Plant Resources, Faculty of Agriculture, Kyushu University

Luna Maldonado, Alejandro Isabel

Faculty of Agriculture, Autonoumus University of Nuevo Lenon, Mexico

Nakaji, kei

Laboratory of Agricultural Ecology, Division of Agricultural Ecology, Graduate School of Bioresources and Bioenvironmental Sciences, Kyushu University

https://doi.org/10.5109/17810

出版情報: 九州大学大学院農学研究院紀要. 55 (1)，pp. 101-105，2010-02-26. Faculty of Agriculture, Kyushu University

バージョン :

権利関係 : 


\title{
Development of an Intelligent Robot for an Agricultural Production Ecosystem (VIII) - Improvement of Predator-Prey Model and Analysis of the Activity of Snail in Paddy by Image Processing -
}

\author{
Yusuke YAMAGUCHI ${ }^{1}$, Alejandro Isabel LUNA MALDONADO² \\ and Kei NAKAJI*
}

\author{
${ }^{1}$ Laboratory of Agricultural Ecology, Division of Agricultural Ecology, \\ Department of Plant Resources, Faculty of Agriculture, \\ Kyushu University, Fukuoka 811-2307, Japan \\ ${ }^{2}$ Faculty of Agriculture, Autonoumus University of Nuevo Leon, Mexico \\ (Received October 29, 2009 and accepted November 19, 2009)
}

\begin{abstract}
The predator (Golden apple snail)-prey (rice or weeds) model developed in a previous research (Luna et $a l ., 2008 \mathrm{c}$ ) and the Simulink model constructed for image processing analysis were improved in order to observe and measure the activity of snails by calculating of speed of them using the AVI (Audio Video Interleave) files reported in earlier paper (Yamaguchi et al., 2008). The improved Predator -Prey Model are thought to be more realistic and the improved Simulink model is able to calculate the speed of two snails at the same time. By introducing these models into the intelligent robot, it will be able to calculate the activity of snails in paddy and determine the more appropriate time of picking up the snails and control the ecosystem of paddy field.
\end{abstract}

\section{INTRODUCTION}

The new conceptual intelligent robot developed by us could make digs or furrows and pick up the snails in paddy field and replaced the work executed by farmers. On the development of a robot, which is operating in artificial ecosystem of agricultural production, it is necessary to understand and develop a model for agricultural ecosystem. The robot must be able to decide how much snails should be removed taking in account productivity of the paddy and the conservation of the agricultural ecosystem by the modeling and after that, the mathematical model for agricultural ecosystem will be set up into the robot memory.

The intelligent robot controls the population or number of golden apple snail in paddy to improve the productivity of the paddy and conserve the agricultural ecosystem. The understanding of the ecosystem of the paddy field is necessary to make the robot and the predator (snail) - prey (rice and weeds) model should be introduced to the robot. Luna et al. (2008) reported the predator - prey model of Lotka-Volterra equation. We modified and improved this Lotka-Volterra equation to make a more realistic model for agricultural ecosystem.

The speed of snails is also a very important parameter to construct the predator - prey model because it consists of the parameters of the previous predator (snail) prey (rice and weeds) model. In this research, a Simulink model was designed to calculate the speed of two snails simultaneously and automatically from AVI (Audio Video Interleave) files recorded in the paddy field.

\footnotetext{
${ }^{1}$ Laboratory of Agricultural Ecology, Division of Agricultural Ecology, Graduate School of Bioresources and Bioenvironmental Sciences, Kyushu University

* Corresponding author (E-mail: knkjfam@mbox.nc.kyushu-u. ac.jp)
}

\section{IMPROVEMENT OF PREDATOR-PREY MODEL}

The Lotka-Volterra model predicts interactions between two species in an ecosystem, a predator and a prey. The predator in the rice production ecosystem is described as a snail whereas prey describes a rice or weed in our case. The model is as follows:

$$
\begin{aligned}
& \frac{d S}{d t}=c p S N-m S \\
& \frac{d N}{d t}=r N-c N S
\end{aligned}
$$

Where $N$ : total density or biomass of superior plants (rice plants and weeds), $S$ : density of snails, $r$ : intrinsic rate of superior plants, $c$ : capture efficiency, $p$ : predators efficiency at turning food into offspring (conversion efficiency), $m$ : mortality rate of snails.

The equation 1 includes the product of the number of predators and the predator mortality rate $(m)$ to describe the rate of decrease of the predator population with respect to time $(t)$. In the presence of prey, however, this decline is opposed by the predator birth rate. The first term $c p S N$ indicates random encounters of predators and victims and is determined by the consumption rate $(c S N$, which is the capture efficiency multiplied by the product of the number of predators times the number of prey) and by the predator's ability to turn food into offspring $(p)$.

In the presence of predators, however, the prey population is prevented from increasing exponentially. The term for consumption rate from above $(c S N)$ describes prey mortality, and the population dynamics of the prey can be described by the equation (2).

We introduced the equations of Holling Type II (Holling, 1959) to the Lotka-Volterra predator-prey model (equations 1 and 2) and divided the parameter of 
capture efficiency to two factors: activity rate of snails and cropping rate; therefore the addition of the new parameter represented by activity rate of snails and cropping rate improve the fitting of the prediction equation to the agricultural production ecosystem. The population dynamics of agricultural production ecosystem is described by the following equation:

$$
\begin{aligned}
& \frac{d S}{d t}=\frac{a d p N S}{1+h N}-m S \\
& \frac{d N}{d t}=r N\left(1-\frac{N}{K}\right)-\frac{a d N S}{1+h N} \\
& a\left(m^{2}\right)=\beta(m / d a y) \times v(m / d a y) \\
& v=f(T), v=f(l)
\end{aligned}
$$

Where $N$ : total density or biomass of superior plants (rice plants and weeds), $S$ : density of snails, $r$ : intrinsic rate of superior plants, $K$ : carrying capacity of superior plants, $a$ : activity rate of snails $d$ : cropping rate, $p$ : predators efficiency at turning food into offspring (conversion efficiency), $m$ : mortality rate of snails, $\beta$ : proportionality factor, $v$ : speed of snails, $T$ : temperature of the water in paddy field, $l$ : water depth of paddy field.

The first term at the bottom of the equation 3 and the second term at the bottom of the equation $4,(h)$ describes the time required by predator for handling, killing and devouring its prey before it can search for another. This is called the "handling time" of the predator. The increase of the predator population and decrease of the prey population are opposed by this handling time. The equation 5 describes the capture efficiency as two new parameters: activity rate and cropping rate. Activity rate of the snails is proportional to their speed and the snail's speed is described as the function of temperature and water depth of paddy field (equation 6).

\section{MATERIALS AND METHODS}

The travel speed of the snail was analyzed using MATLAB, Simulink, their Toolboxes and Blocksets. A video was filmed of the moving snails by a Field Server in the paddy field (Figure 1). A Field Server was used for recording three frames in jpg format per second. From these pictures, AVI files were created by MATLAB.

The Simulink model calculates the coordinates of the centroids of the snails and send those data to MATLAB Workspace, which is shown in Figure 2. The Simulink model shown in Figure 3 is the subsystem of the previous model (Figure 2). This model imports the AVI files and extracts only snails from those files of the movie.

Display block is connected to the Blob Analysis block in this model. The Draw Markers block can draw multiple circles, $\mathrm{x}$-marks, positive signs, stars, or squares on images by overwriting pixel values. As a result, the shapes are attached on the output image. The symbols of plus sign for representing the coordinates of centroid were set up. Then the coordinates of the centroid of snail of each frame in the AVI file were sent to MATLAB Workspace through the To Workspace block.

Yamaguchi et al., 2008 could extract one snail in the previous paper, we were able to extract all snails in the movie by setting wider range of $\mathrm{L}^{*} \mathrm{a} \mathrm{b}^{*}$ values. The range of L*a*b* values were set at 30 to 76,123 to 128 and 118 to 127 , respectively. We compared the distance of two centroids with that of the measured in the AVI file and found one pixel corresponds to about $1.43 \mathrm{~mm}$. The video camera of the Field Server tilted with an angle of about 30 degree to the ground. The distance was calculated using equation the following equation:

$$
D=\sqrt{((x 2-x 1) * 0.43)^{2}+\left(\frac{(y 2-y 1) * 1.43}{\cos \theta}\right)^{2}}
$$

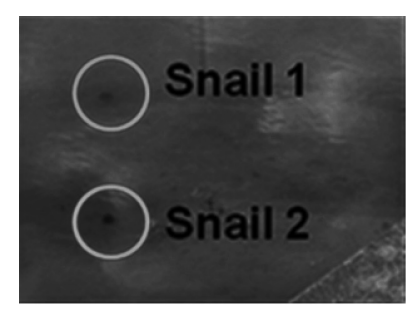

$1 / 4$

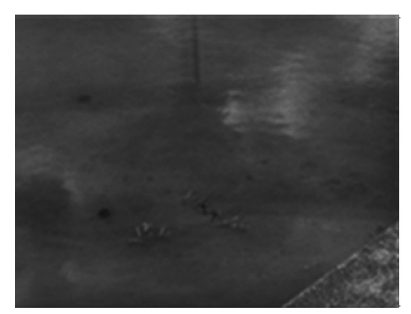

$3 / 4$

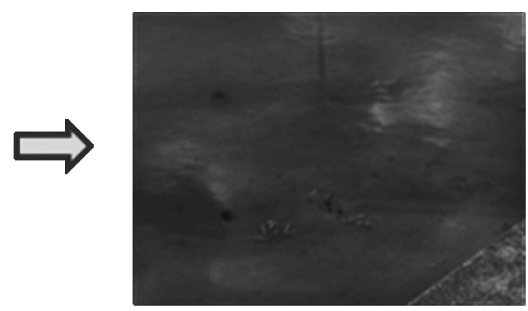

$2 / 4$

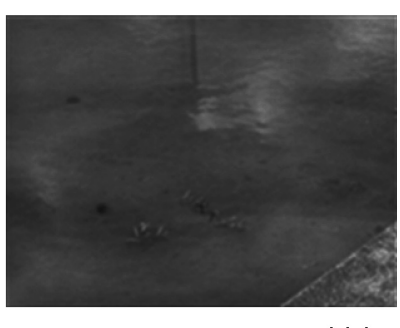

$4 / 4$

Fig. 1. Sequence of four frames of the movie of two snails moving in paddy for 19 seconds on the crop season of 2008. 


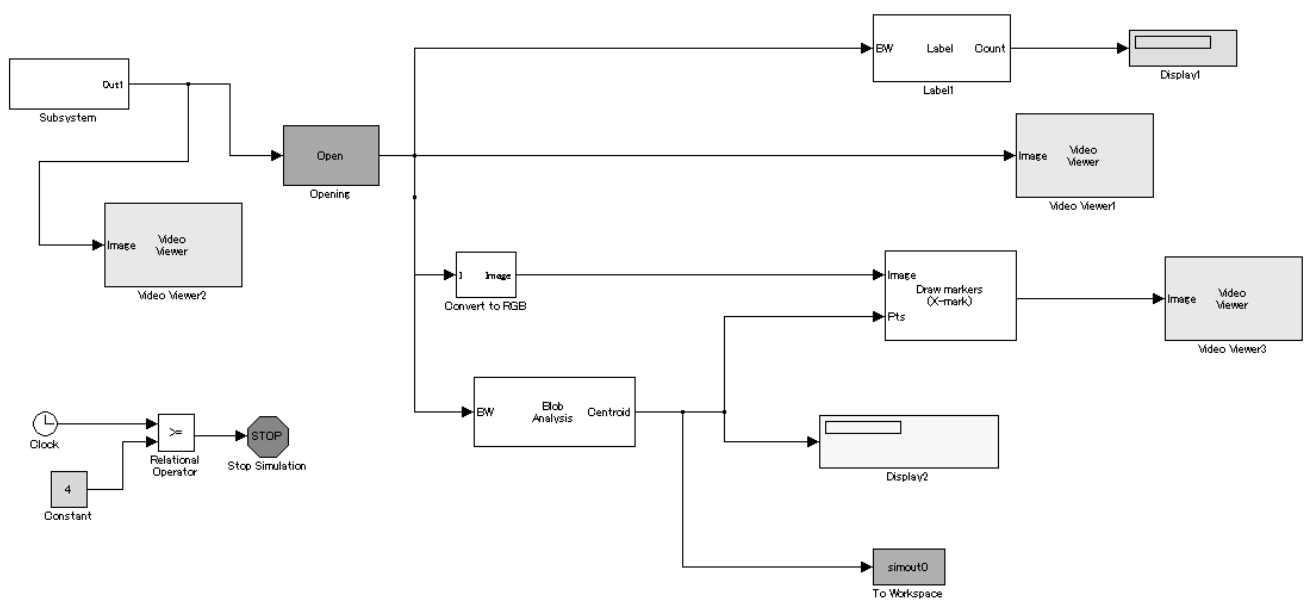

Fig. 2. Simulink model to calculate the coordinates of the snails and send those data to MATLAB Workspace from the AVI files of Figure 1.

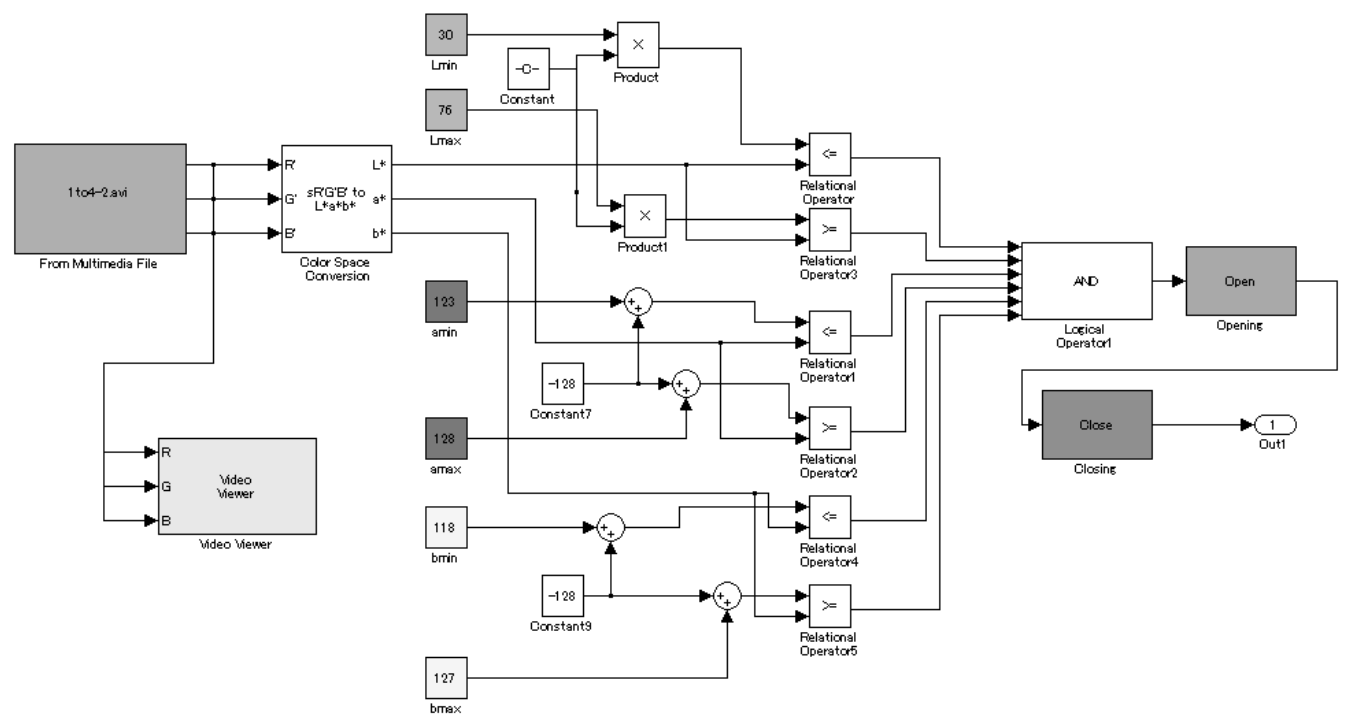

Fig. 3. The subsystem of the Simulink model of Figure 2.

Where

$D=$ traveled distance by the snail in paddy or laboratory

$\theta=$ tilt angle of the camera, in this case 30 degrees

$x_{1}$ : abscissa of the centroid 1

$x_{2}:$ abscissa of the centroid 2

$y_{1}:$ ordinate of the centroid 1

$y_{2}:$ ordinate of the centroid 2

Instantaneous speed of the snails and average speed were calculated in each case using the distance obtained by equation 7 and time given by Field Server, which recorded the movie.

\section{RESULTS}

Four frames were obtained with the centroids marked as plus signs of moving snails from the AVI files in paddy (Figure 1). The coordinates of centroid of snails are shown in Figure 4.
The coordinates of centroid are automatically exported to the Matlab workspace through of the To Workspace block and we can be able to calculate the

Table 1. Travel distance and speed of snails in the laboratory and in the paddy

\begin{tabular}{cccc}
\hline & $\begin{array}{c}\text { Time interval } \\
\text { (second) }\end{array}$ & $\begin{array}{c}\text { Distance } \\
(\mathrm{mm})\end{array}$ & $\begin{array}{c}\text { Instantaneous speed } \\
\text { (mm/second) }\end{array}$ \\
\hline \multirow{3}{*}{ Snail 1 } & $0 \sim 5$ & 13.0 & 1.9 \\
& $5 \sim 12$ & 28.8 & 5.8 \\
& $12 \sim 25$ & 11.9 & 1.7 \\
\hline \multirow{3}{*}{ Snail 2} & $0 \sim 5$ & Average Speed $2.8 \mathrm{~mm} / \mathrm{s}$ \\
& $5 \sim 12$ & 15.5 & 1.2 \\
& $12 \sim 25$ & 11.6 & 3.0 \\
\hline \multicolumn{3}{c}{ Average Speed $1.9 \mathrm{~mm} / \mathrm{s}$} \\
\end{tabular}


$1 / 4$

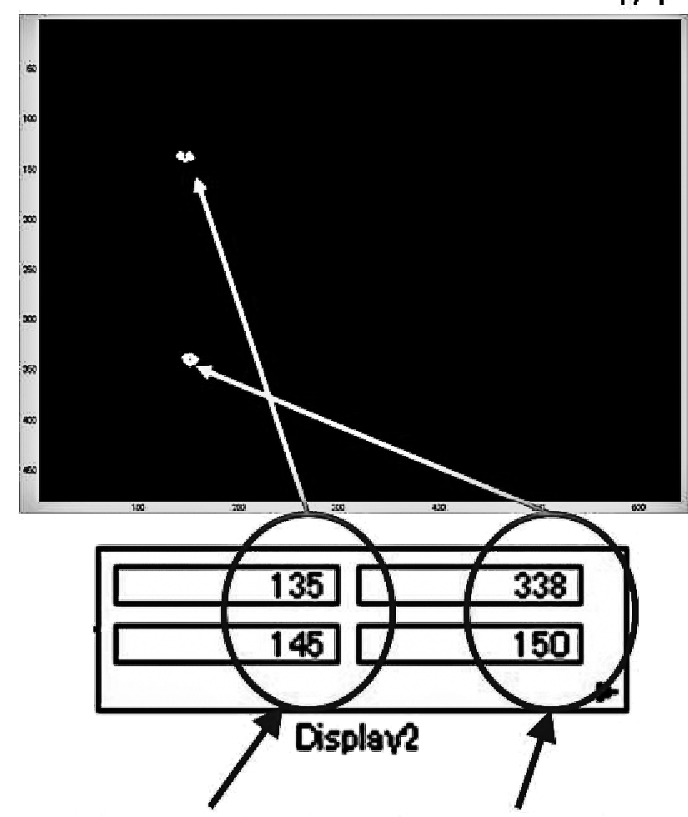

The coordinate The coordinate of the centroid of the centroid of snail 1 of snail 2
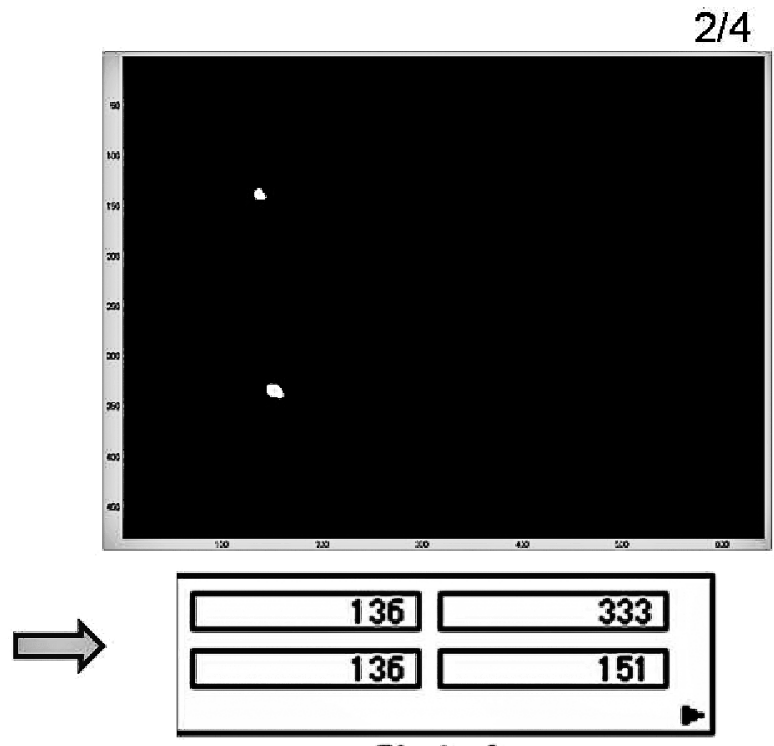

Displav2

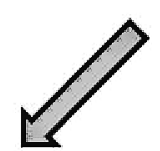

$3 / 4$
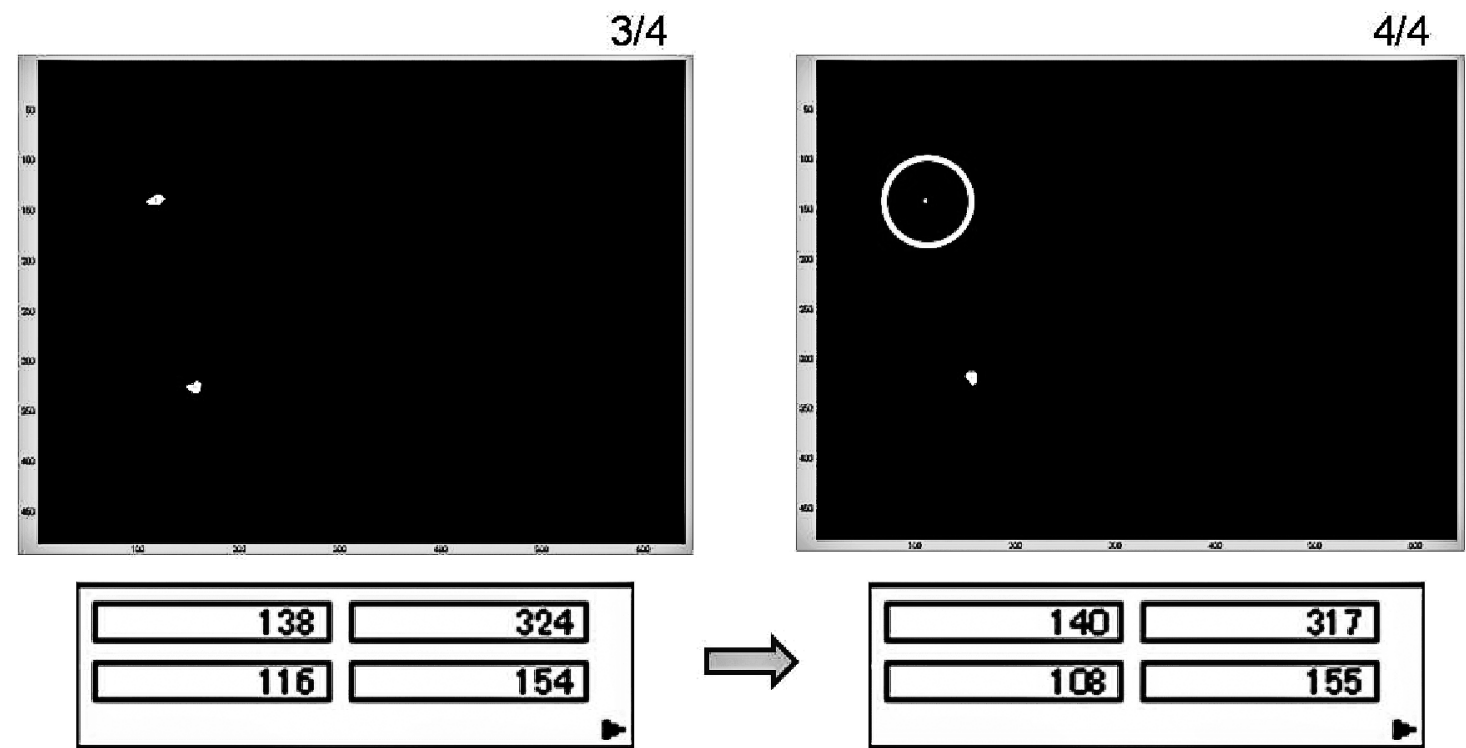

Displav2

Fig. 4. Centroids of two snails marked by blues plus signs in four frames of the AVI file of Figure 1 and coordinates of the centroids of two snails.

speed of the snail via $m$ file program and export those data to an Excel file.

The data of speed of two snails calculated by the Simulink model and the m-files are shown on Table 1.

The actual speed of the snail in the laboratory was already compared with the speed obtained from Simulink model in the previous paper (Yamaguchi et al., 2008) and it was found to be highly consistent with real one. Therefore it was thought that these data of snails speed were also consistent with real one.

\section{CONCLUSION AND DISCUSSION}

The more realistic predator (snail) - prey (rice and weeds) models were developed. The speed of all snails in the movie recorded by the Field Server can be calculated by the Simulink model constructed this time and therefore the parameters of the predator (snail) - prey model (rice and weeds) (equations 3, 4 and 5) such as activity rate of snails can be estimated by its travel speed in the paddy using the processing of AVI files. The relational expression of the speed of snails and temperature 
or the depth of water will have to be constructed in the future to complete the identification of the parameter for the predator - prey model and to improve the estimation of the populations of the species involved in production ecosystem of paddy.

\section{REFERENCES}

Damoto R., K. Sakai, S. Shibusawa and A. Sasao 2003 The White Clover-Winter Weed SystemCompetition Dynamics. The Difference of white clover preceding crop ground and sweet corn preceding crop ground. Grassland Science, 49: 141-148

Holling, C. S. 1959 The components of predation as revealed by a study of small mammal predation of the European Pine Sawfly. Canadian Entomologist, 91: 293-320

Luna Maldonado, A. I. and K. Nakaji 2008a Development of an Intelligent Robot for an Agricultural Production EcosystemNew Concept of Robot and Dynamics of a Golden Apple Snail in Paddy-. Journal of the Faculty of Agriculture, Kyushu University, 53: 115-119

Luna Maldonado, A. I., Y. Yamaguchi, M. Tuda and K. Nakaji 2008a Development of an Intelligent Robot for an Agricultural Production Ecosystem (II)- Modeling of the Competition between rice plants and weeds -. Journal of the Faculty of Agriculture, Kyushu University, 54: 511-516

Luna Maldonado, A. I., Y. Yamaguchi, M. Tuda and K. Nakaji 2008b Development of an Intelligent Robot for an Agricultural Production Ecosystem (III) - Modeling of the Predation of Rice Plants and Weeds by Golden Apple Snail-. Journal of the Faculty of Agriculture, Kyushu University, 54: 517-525

Luna Maldonado, A. I., Y. Yamaguchi and K. Nakaji 2009c Development of an Intelligent Robot for an Agricultural Production Ecosystem (IV) - Experiments on Growth and Competition of Rice Plants against Weeds -. Journal of the Faculty of Agriculture, Kyushu University, 54: 231-233

Luna Maldonado, A. I., Y. Yamaguchi and K. Nakaji 2009d
Development of an Intelligent Robot for an Agricultural Production Ecosystem (V) - Experiments on Predation of Paddy by Golden Apple Snails-. Journal of the Faculty of Agriculture, Kyushu University, 54: 235-239

Luna Maldonado, A. I., Y. Yamaguchi and K. Nakaji 2009e Development of an Intelligent Robot for an Agricultural Production Ecosystem (VI) -Counting of Snails in Laboratory and Paddy by Image Processing -. Journal of the Faculty of Agriculture, Kyushu University, 54: 241-245

Yamaguchi Y., A. I. Luna Maldonado and K. Nakaji 2009 Development of an Intelligent Robot for an Agricultural Production Ecosystem (VII) - Image Processing and Analysis of the Activity of Snail in Paddy-. Journal of the Faculty of Agriculture, 54: 247-250

MATHWORKS. Video and Image Processing Blockset.User's guide. Matlab and Simulink, USA

Mc Andrew A. 2008 An Introduction to Digital Image Processing with Matlab. Notes of SCM2511 Image Processing I. School of Computer Science and Mathematics, Victora University of Technology. （sci.vu.edu.au/ amca/SCM2511/book2511.pdf) Australia, pp. 1-257

Miezianko R. 2008 Creating AVI movie frames in Matlab. Computer and Information Science Department, Temple University. Philadephia, (astro.temple.edu/ rmiezian/pubs/ CreateAVIframesInMatlab.pdf) USA, pp. 1-4

Nakaji, K., N. Niidome and K. Ikeda 1998 Rice Cropping for Paddy Ecosystem based on the High Technology System (Part I) Experimental System to Observe the Behavior of Golden Apple Snail-. Journal of the Japanese Society of Agricultural Machinery, 56: 123-124

Tuda, M. and Shimada, M. 2005 Complexity, evolution and persistence in host-parasitoid experimental systems, with/ Callosobruchus/ beetles as the host. Advances in Ecological Research 37,pp. 37-75

UMASS LOWELL 2006 Importing and exporting data from MATLAB and Simulink to Excel. Dynamic systems. University of Massachusetts Lowell (faculty.uml.edu/.../22.451/Simulink_ importing_exporting_to_excel.pdf), USA, pp.1-4 